\title{
Spectroscopic properties of macrocyclic oligo(phenyldiacetylenes)-II. Synthesis and theoretical study of diacetylenic dehydrobenzoannulene derivatives with weak electron-donor and -acceptor groups $^{*}$
}

\author{
Boris Zimmermann, Goranran Baranović , Zoran Štefanić, Marko Rožman
}

\begin{abstract}
Diacetylenic dehydrobenzo[12]annulene and dehydrobenzo[18]annulene derivatives with electron-donor and -acceptor groups were synthesized (including push-pull Eglinton-Galbraith dimer derivative 1c) via an oxidative coupling reaction, and spectroscopically and structurally characterized. The solid-solid phase transition in $\mathbf{1 b}$ has been revealed at $45^{\circ} \mathrm{C}$ by DSC measurements. Its room temperature crystal structure has been solved by X-ray diffraction measurements. The ${ }^{1} \mathrm{H}$ and ${ }^{13} \mathrm{C}$ NMR chemical shifts, UV/vis and infrared absorption spectra and Raman scattering spectra have been analyzed by using ground-state DFT calculations. The strongest absorptions in the UV/vis spectra of $\mathbf{1}$ and 2 most probably are not due to the HOMO $\rightarrow$ LUMO excitations but due to the $(\mathrm{HOMO}-1) \rightarrow$ LUMO and HOMO $\rightarrow(\mathrm{LUMO}+1)$ excitations. The substitution effects on the electronic charge distribution of the all-carbon annulenic cores can be particularly well observed in the distribution of IR intensities in the region of acetylenic stretching vibrations. IR intensities are thus useful in studying the extent of resonance interactions also in acetylenic macrocycles.
\end{abstract}

Keywords: Dehydrobenzoannulenes; Diphenyldiacetylenes; Aromaticity; Donor; Acceptor; Substituent effects; Resonance interaction; Vibrational spectroscopy

\section{Introduction}

Dehydrobenzoannulenes have the potential of forming expanded carbon-rich networks [1-5] potentially leading to the theoretically predicted carbon allotropes [6,7]. Regarding their highly conjugated structure, these compounds have intensively been studied [8-14] as promising candidates for innovative electronic and photonic materials [15]. The donor/ acceptor dehydrobenzo[18]annulenes attracted special interest given that this kind of push-pull systems is good candidates for use in non-linear optics [16,17]. At the same time, related donor/acceptor dehydrobenzo[12]annulenes remained unexplored with respect to their ability of providing a communication through the conjugated bridge. With that in mind we attempted to create in a similar way dimer derivatives with

\footnotetext{
${ }^{45}$ For part I see Ref. [37].
}

electron acceptor groups, as a first step in synthesis of a pushpull dimeric macrocycle.

Highly strained Eglinton-Galbraith dimer $1 a\left(R_{1}=R_{2}=H\right.$, Scheme 1) was synthesized more than 40 years ago [18], but until last decade it did not draw attention, mainly because of its high instability in the solid state [19]. However, different derivatives of this dimer were successfully synthesized showing much higher crystal stability $[14,20,21]$. Bunz and Enkelmann concluded that the solid-state reactivity of this dimer is not a property of the individual molecule due to the strained nature of the bent butadiyne bridges, but is merely guided by the packing arrangements of the diyne groups [19]. Swager's group prepared derivatives of Eglinton-Galbraith dimer containing electron-donating alkyl and alkoxy groups [14] and the presence of long side-chains stabilized the crystal. In view of the fact that solubility of dehydrobenzoannulenes is decreasing with increasing molecule size [3], it would be of interest to create this kind of relatively small dehydrobenzoannulenes. Here, we report our results on the synthesis and characterization of dehydrobenzo[12]annulenes and dehydrobenzo[18]annulenes with ester and alkyl side-chains. An attempt has been consequently undertaken to understand 

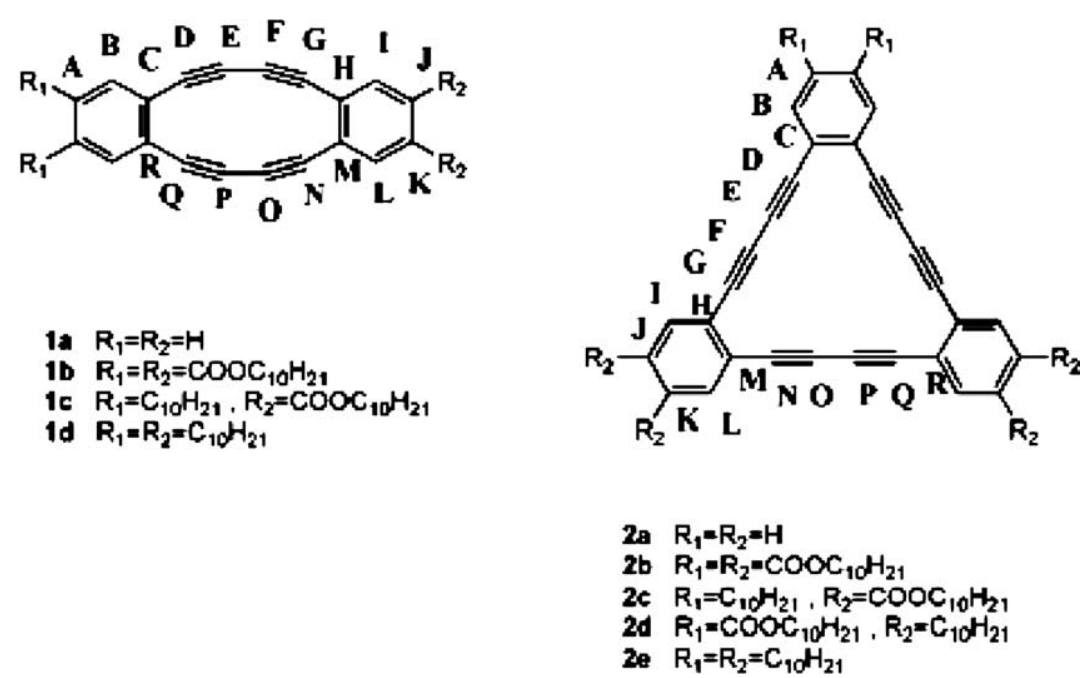

Scheme 1.

the substitutional effects on electronic properties of acetylenic macrocycles.

\section{Experimental}

\subsection{General}

${ }^{1} \mathrm{H}$ and ${ }^{13} \mathrm{C}$ NMR spectra were recorded on a Bruker Avance 300 and Bruker Avance 600 spectrometer. The chemical shifts of NMR are expressed in ppm from TMS as determined with reference to the internal $\mathrm{CHCl}_{3}$ and $\mathrm{CDCl}_{3}\left(\delta 7.26{ }^{1} \mathrm{H} \mathrm{NMR}\right.$ and $\left.\delta 76.9{ }^{13} \mathrm{C} \mathrm{NMR}\right)$. UV/vis spectra were taken on a Varian Cary 50 spectrometer. Melting points were measured on an Olympus System Microscope BX51TF with Linkam hot stage. The Central Analytical Service, Rudjer Bošković Institute, Zagreb, performed elemental analyses. Infrared spectra were recorded on a Bomem MB102 spectrometer. Raman spectra were taken on a Bruker FT-Raman 106/S spectrometer (Faculty of Sciences, University of Zagreb). All mass spectra were obtained using a Finigan 2001 DD (Finigan, Madison, WI, USA) Fourier transform mass spectrometer equipped with a Nd: YAG Quanta Ray DCR-11 laser (Spectra-Physics Inc., Mountain View, CA, USA) emitting at $\lambda=1064 \mathrm{~nm}$ and a nitrogen laser (VSL 337 NSD, LSI Laser Science, Newton, USA) emitting at $\lambda=337 \mathrm{~nm}$. Following a quench pulse, positive/negative ions were formed by a single laser pulse. All mass spectra were recorded at $100 \mu$ s time delay.

\subsection{X-ray structural determination}

Crystal data for $\mathbf{1 b}$ : yellow crystals, $\mathrm{C}_{64} \mathrm{H}_{88} \mathrm{O}_{8}, M=985.34$, monoclinic, space group $P 2_{1} / c$ (no. 14), $a=13.444$ (4), $b=$ 9.352 (2), $c=23.741$ (9) $\AA, \alpha=90.00, \beta=94.15$ (3), $\gamma=$ $90.00^{\circ}, V=2977.1(16) \AA^{3}, Z=2, D_{\mathrm{c}}=1.099 \mathrm{gcm}^{-3}, T=293$ (2) $\mathrm{K}, \mu(\mathrm{Cu}-\mathrm{K} \alpha)=0.554 \mathrm{~mm}^{-1}, 6395$ reflections measured, 6238 unique reflections $\left(R_{\mathrm{int}}=0.019\right), R_{\mathrm{w}}=0.190$ (all data), $R_{1}=0.0641(I>2 \sigma)$. Intensities were measured on an Enraf Nonius CAD4 diffractometer, with graphite monochromated
$\mathrm{Cu} \mathrm{K} \alpha$ radiation, wavelength $1.54180 \AA$, using the $\omega / 2 \theta$ scan technique. During data collections there were no significant variations in intensities of the three control reflections, which were measured every $120 \mathrm{~min}$. The data were corrected for Lorentz and polarization effects [22]. The absorption correction was based on a $\psi$-scan of seven reflections. Structures were solved using WinGX package [23] and refined by the package SHELXL97 [24]. Molecular geometry calculations and illustrations of the crystal packing were prepared by PLATON98 [25]. Atomic scattering factors were those included in SHELXL97. Crystallographic data excluding structure factors for the structures reported in this paper have been deposited with the Cambridge Crystallographic Data Centre as supplementary publication number CCDC 216872. Copies of data can be obtained, free of charge, on application to CCDC, 12 Union Road, Cambridge CB2 1EZ, UK (fax: + 441223 336033 or e-mail: deposit@ccdc.cam.ac.uk).

\subsection{Computational}

Full geometry optimization and calculations of vibrational frequencies and IR intensities were carried out at a B3LYP level of DF theory with a $6-31+\mathrm{G}^{*}$ basis set. All the calculations were performed with the GAUSSIAN03 software package [26]. The chosen basis set when used with the chosen functional for the calculations of geometry and vibrational frequencies of hydrocarbons has been described as adequate [27].

\section{Results and discussion}

\subsection{DSC measurements}

Compounds $\mathbf{1 b}-\mathbf{c}$ are bright yellow solids and can be stored for weeks at $4{ }^{\circ} \mathrm{C}$ without decomposition. With decomposition that began above $50{ }^{\circ} \mathrm{C}$ donor/acceptor-substituted macrocycle 1c showed lowest thermal stability in comparison to alkyl derivative $1 \mathbf{d}$ (decomposition around $100{ }^{\circ} \mathrm{C}$ ) [14] and ester 


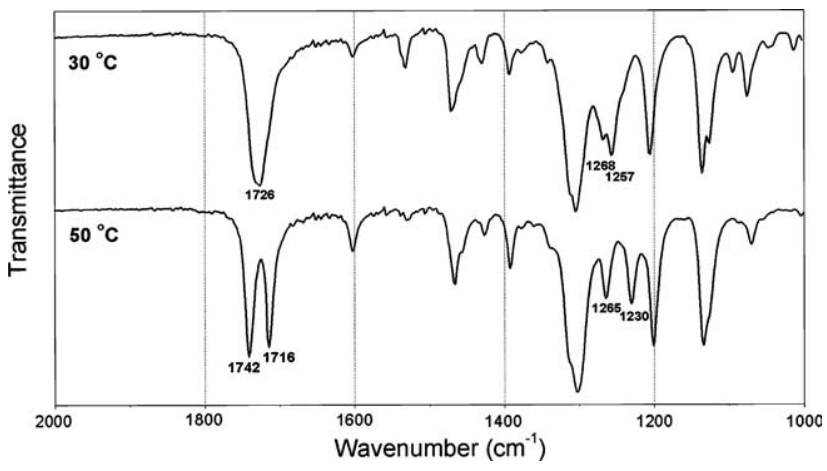

Fig. 1. Infrared spectra of $\mathbf{1 b}$ at 30 and $50^{\circ} \mathrm{C}$.

derivative 1b. Differential scanning calorimetry showed that decomposition of $\mathbf{1 b}$ began above $70^{\circ} \mathrm{C}$. This is an extremely exothermic process (enthalpy value of $426 \mathrm{~kJ} / \mathrm{mol}$ ) occurring over a relatively narrow $15-20{ }^{\circ} \mathrm{C}$ range $\left(w^{1 / 2}=6^{\circ} \mathrm{C}\right)$. Similar to the long chain alkyl derivative $\mathbf{1 d}$, the compound $\mathbf{1 b}$ shows an additional endothermic peak at $45{ }^{\circ} \mathrm{C}$ presumably due to crystal-to-crystal phase transition. This transition is obvious if we compare IR spectra of the compound $\mathbf{1 b}$ at 30 and $50{ }^{\circ} \mathrm{C}$, particularly the carbonyl band and $1250 \mathrm{~cm}^{-1}$ regions (Fig. 1).

\subsection{X-ray crystallography}

The crystal structure of $\mathbf{1 b}$ was solved by X-ray diffractometry on single crystals obtained from dichloromethane. The butadiyne bridges show expected deviation from linearity (Table 1) in agreement with the values described in the literature [14]. The shortest contacts of an annulene ring are found with the carbonyl oxygens of the two alkyl chains lying in the plane of the ring. Any of the annulene rings is thus parallel to the chains of the neighboring molecules (Fig. 2) and not to adjacent rings contrary to the packing of Eglinton-Galbraith dimer 1a $\left(\mathrm{R}_{1}=\mathrm{R}_{2}=\mathrm{H}\right)$ [19], its alkyl [14], alkynyl [13] and fluoro derivatives [21], where the parallel stacking of planar annulene rings determines the crystal structure. Half of the chains are laid out in the all-trans (planar zig-zag) conformation, while the other half exhibit gauche deformation beginning with the oxygen atom. Although the gauche conformation is thermodynamically less favored it enables the ester chain to be parallel to the adjacent chain thus leading to the optimal crystal packing. The angles for the two adjacent (CO)OC groups relative to the annulene plane are 31 and $52^{\circ}$ (calculated values are 22 and $26^{\circ}$, respectively), which is significant. As a consequence of the deviation from planarity the (CO)OC $\pi$-molecular orbitals will remain localized with minimal overlap with the annulene $\pi$-orbitals. Thus, only the intramolecular interaction between the diyne units is possible and since the distance between the a-type carbons (Scheme 1) is only $3.232 \AA$, the intramolecular cyclization is highly probable at higher temperatures.

The agreement between the $\mathrm{X}$-ray structure and the B3LYP/6-31+G* optimized bond lengths is reasonable (Table 1) although the triple bond length is systematically overestimated by $0.02 \AA$, while the central C-C bond length is calculated shorter by the same value. As a measure of the ring deformation due to the substitution that preserves $C_{2}$ symmetry of a benzene ring the quantity $\delta=(1 / 2)(H M-J K+(H I+$ $L M) / 2-(I J+K L) / 2)$ might be useful (Scheme 1). Its non-zero value certainly is a consequence of the HM bond elongation due to the strained nature of the [12] annulenic ring. However, according to calculations the value of $\delta$ even for the unstrained 2a should be different from zero and close to the value calculated for the strained 1a.

Table 1

Selected bond distances and angles for some macrocyclic oligo(phenyldiacetylene) structures

\begin{tabular}{|c|c|c|c|c|c|c|c|c|c|c|}
\hline \multirow{2}{*}{$\begin{array}{l}\text { Bond/ } \\
\text { Angle }^{\mathrm{a}}\end{array}$} & \multicolumn{2}{|l|}{ 1a } & \multicolumn{2}{|l|}{$1 \mathrm{a}$} & \multirow{2}{*}{$\begin{array}{l}\text { 1b } \\
\text { Obs. }\end{array}$} & \multirow{2}{*}{$\begin{array}{l}\text { 1b } \\
\text { Calc. }\end{array}$} & \multirow{2}{*}{$\begin{array}{l}\mathbf{2 a} \\
\text { Calc. }\end{array}$} & \multirow{2}{*}{$\begin{array}{l}\mathbf{2 b} \\
\text { Calc. }\end{array}$} & \multirow{2}{*}{$\begin{array}{l}\mathbf{2 e} \\
\text { Calc. }\end{array}$} & \multirow{2}{*}{$\begin{array}{l}\mathbf{d p b}^{\mathrm{b}} \\
\text { Obs. }\end{array}$} \\
\hline & Obs..$^{c}$ & Obs. ${ }^{\mathrm{d}}$ & Obs. ${ }^{\mathrm{e}}$ & Calc. & & & & & & \\
\hline CD & 1.430 & 1.429 & 1.437 & 1.425 & 1.438 & 1.424 & 1.417 & 1.416 & 1.417 & 1.421 \\
\hline $\mathrm{DE}$ & 1.190 & 1.218 & 1.196 & 1.224 & 1.196 & 1.223 & 1.223 & 1.223 & 1.224 & 1.199 \\
\hline $\mathrm{EF}$ & 1.381 & 1.368 & 1.380 & 1.363 & 1.376 & 1.362 & 1.358 & 1.357 & 1.358 & 1.374 \\
\hline FG & 1.186 & 1.217 & & & 1.196 & & & & & \\
\hline GH & 1.446 & 1.428 & & & 1.438 & & & & & \\
\hline HM & 1.364 & 1.401 & 1.414 & 1.439 & 1.419 & 1.438 & 1.429 & 1.428 & 1.425 & - \\
\hline$\delta^{\mathrm{f}}$ & - & 0.007 & 0.032 & 0.024 & 0.011 & 0.016 & 0.019 & 0.013 & 0.011 & - \\
\hline $\mathrm{CDE}$ & 166.4 & 165.7 & 165.3 & & 166.1 & 164.3 & & & & \\
\hline DEF & 167.0 & 167.3 & 167.3 & & 168.5 & 167.6 & & & & \\
\hline EFG & & 166.9 & & & 167.6 & 167.7 & & & & \\
\hline FGH & & 163.9 & & & 166.9 & 164.2 & & & & \\
\hline GHM & 117.6 & 117.0 & 117.3 & 117.9 & 116.9 & 118.1 & & & & \\
\hline
\end{tabular}

${ }^{\text {a }} \mathrm{CD}$ is a bond length $(\AA)$ between atoms $\mathrm{C}$ and $\mathrm{D}$, etc. (Scheme 1$)$.

b Diphenyldiacetylene crystal structure [29]. The crystal structures of unsymmetrically substituted dehydrobenzo[18]annulenes are known [16] and are unsuitable for comparison with the calculated molecular structures.

c This is a dehydro[12]annulene molecule with $-\mathrm{C} \equiv \mathrm{C}-\mathrm{Si}(\mathrm{iPr})_{3}$ groups instead of hydrogens [28].

${ }^{\mathrm{d}}$ See Tovar et al. [13] for the structure of a dehydrobenzo[12]annulene molecule where all hydrogens have been replaced by the $-\mathrm{C} \equiv \mathrm{C}-t \mathrm{Bu}$ groups.

e Ref. [21].

${ }^{\mathrm{f}} \delta=(1 / 2)(H M-J K+(H I+L M) / 2-(I J+K L) / 2)($ Scheme 1$)$. 


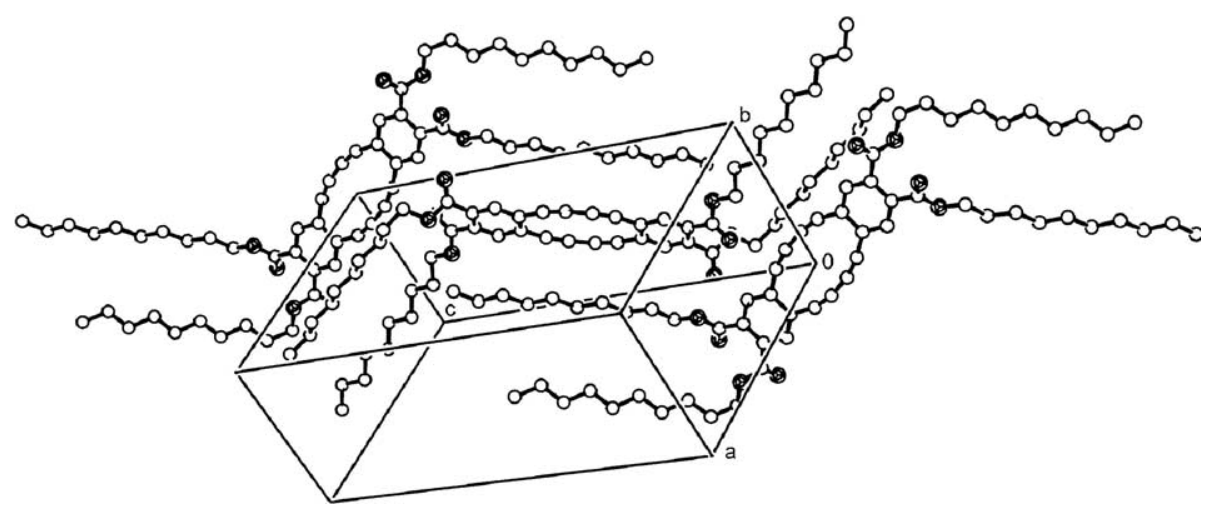

Fig. 2. ORTEP packing diagram of $\mathbf{1 b}$ showing the unit cell structure.

\section{3. ${ }^{1} \mathrm{H}$ and ${ }^{13} \mathrm{C}$ NMR spectra}

The anti-aromatic nature of dehydrobenzo[12]annulene ring as well as aromatic nature of dehydrobenzo[18]annulene ring was confirmed by comparing their ${ }^{1} \mathrm{H}$ NMR spectra with spectra of acyclic diethynylbenzenes $\mathbf{3}$ (see Supplementary material) and unsubstituted 1a [30] and 2a [31,32] (Scheme 1 and Table 2). The arene protons of dimers 1 undergo a $0.5 \mathrm{ppm}$ upfield (paratropic) shifts relative to $\mathbf{3}$, while trimeric macrocycles 2 show $0.2 \mathrm{ppm}$ downfield (diatropic) shifts. As already speculated [32] the weakness in diatropicity and paratropicity of these macrocycles might be due to benzannelation. However, if these systems are able to sustain the circular current only as a single loop of electrons (no current through the bonds shared by the two types of rings) it is then more correct to ask whether the unsubstituted octadehydrodiben$\mathrm{zo}[12]$ annulene system is aromatic or not and analogously for the unsubstituted dodecadehydrotribenzo[18]annulene system. In other words, the central annulenic ring should not be treated as a separate entity when the fused benzene rings are present.

The observed ${ }^{13} \mathrm{C}$ NMR spectra (Supplementary material) show that all the compounds, $\mathbf{1 b}-\mathbf{d}$ and $\mathbf{2} \mathbf{b}-\mathbf{e}$, possess in solution at least an effective $C_{2}$ symmetry. The calculated 1c structure has no such symmetry (when, for example, Mulliken atomic charges are viewed) although the alkyl half of the molecule locally has the $C_{2}$ symmetry axis along the long

Table 2

${ }^{1} \mathrm{H}$ NMR data of arene protons of $\mathbf{1}, \mathbf{2}$ and $\mathbf{3}$ (Scheme A1 in Supplementary material) in $\mathrm{CDCl}_{3}$

\begin{tabular}{llll}
\hline Molecule & $\delta \mathrm{H}^{\prime}$ & $\delta \mathrm{H}^{\prime \prime}$ & $\delta \mathrm{H}^{\prime \prime \prime}$ \\
\hline $\mathbf{3 c}$ & 7.29 & & \\
$\mathbf{3 f}$ & 7.83 & & \\
$\mathbf{1 a}$ & 7.06 & & \\
$\mathbf{1 b}$ & 7.28 & 7.23 & \\
$\mathbf{1 c}$ & 6.78 & & \\
$\mathbf{1 d}$ & 6.76 & & \\
$\mathbf{2 a}$ & 7.68 & 7.97 & 8.01 \\
$\mathbf{2 b}$ & 8.02 & 7.46 & 7.45 \\
$\mathbf{2 c}$ & 7.49 & & \\
$\mathbf{2 d}$ & 7.96 & & \\
$\mathbf{2 e}$ & 7.44 & & \\
\hline
\end{tabular}

\footnotetext{
${ }^{a}$ Ref. [30].

b Refs. [5,31].
}

molecular axis. Similarly the atomic charges in the structures 2c and 2d are sensitive to the torsional angles of the ester groups while the observed ${ }^{13} \mathrm{C}$ NMR shifts indicate a $C_{2}$-axis lying in the molecular plane.

\subsection{UV/vis spectra}

Before starting any discussion of the recorded UV/vis spectra it is instructive to analyze the molecular orbital plots particularly when charge transfer transitions are suspected [33]. The molecular and accompanying electronic structures have here been predicted by using DFT and the subsequent discussion implies (a) that the Kohn-Sham molecular orbitals are similar to the Hartree-Fock orbitals and (b) the acceptance of the possibility to interpret excited electronic states only in terms of singly excited configurations formed from the KohnSham orbitals. The central benzoannulenic core in $\mathbf{1 a}, \mathbf{1 b}$ and 1d obviously has $D_{2 h}$ symmetry, while in $\mathbf{1 c}$ this symmetry is weakly perturbed. Therefore, the one-electron HOMO $\left(\mathrm{B}_{2 \mathrm{~g}}\right)$ LUMO $\left(\mathrm{B}_{1 \mathrm{~g}}\right)$ transition, $\mathrm{A}_{1 \mathrm{~g}} \rightarrow \mathrm{B}_{3 \mathrm{~g}}$ (the long molecular axis is $z$-axis while the $x$-axis is perpendicular to the molecular plane), is forbidden in the former three compounds while only weakly allowed in the latter (Fig. 3). Similarly, the central benzoannulenic core in $\mathbf{2 a}, \mathbf{2 b}$ and $\mathbf{2 e}$ obviously has $D_{3 h}$ symmetry, while in $\mathbf{2 c}$ and $\mathbf{2 d}$ this symmetry is weakly perturbed (Fig. 4). The HOMO and LUMO are both degenerate $\mathrm{E}^{\prime \prime}$ orbitals and by promoting single electron four different electronic states are formed, $\mathrm{A}_{1}{ }^{\prime}+\mathrm{A}_{2}{ }^{\prime}+\mathrm{E}^{\prime}$, where only the transition $\mathrm{A}_{1}{ }^{\prime} \rightarrow \mathrm{E}^{\prime}$ is allowed that is not necessarily the lowest.

The electronic absorption spectra of 1 (Fig. 5, Tables 3 and 4) exhibit the characteristic pattern found for dehydrobenzoannulene cores (1a in [18], alkoxy derivatives of $\mathbf{1 a}$ in [34] and 2a in [5]). The spectra of $\mathbf{1}$ are dominated by the band at $\sim 310 \mathrm{~nm}$ which presents a shift of $\sim 40 \mathrm{~nm}$ in comparison with the average location of the most prominent doublet in the spectrum of, for example, $\mathbf{3 f}$. The corresponding shift for $\mathbf{2}$ is $\sim 65 \mathrm{~nm}$. In comparison with electron-donating derivatives, the UV/vis spectra of ester macrocycles $\mathbf{1 b}$ and $\mathbf{2 b}$ showed small but distinct red shift (ca. $8 \mathrm{~nm}$ ). The alkyl/estersubstituted [12]annulene 1c showed two new absorption bands at 307 and $326 \mathrm{~nm}$ (Fig. 5). Given that the compound 1c is donor/acceptor substituted $\pi$-conjugated system it is 

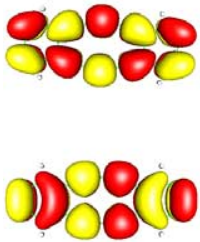

$1 a$

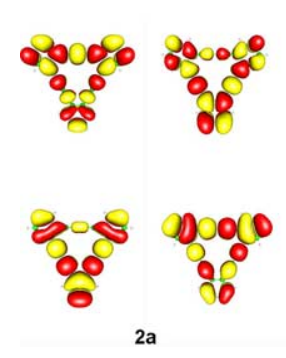

$2 a$
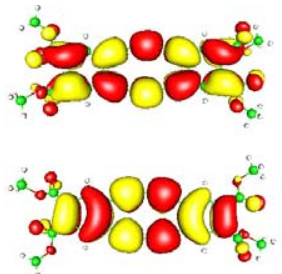

$1 \mathrm{~b}$
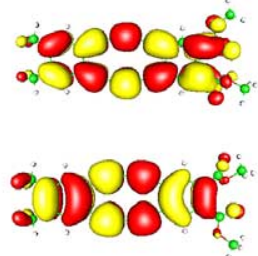

$1 c$

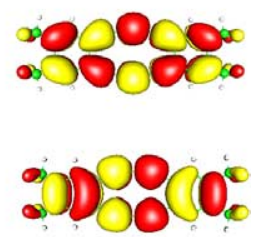

$1 d$

Fig. 3. LUMO plots (up) and HOMO plots (down) of 1a-1d.
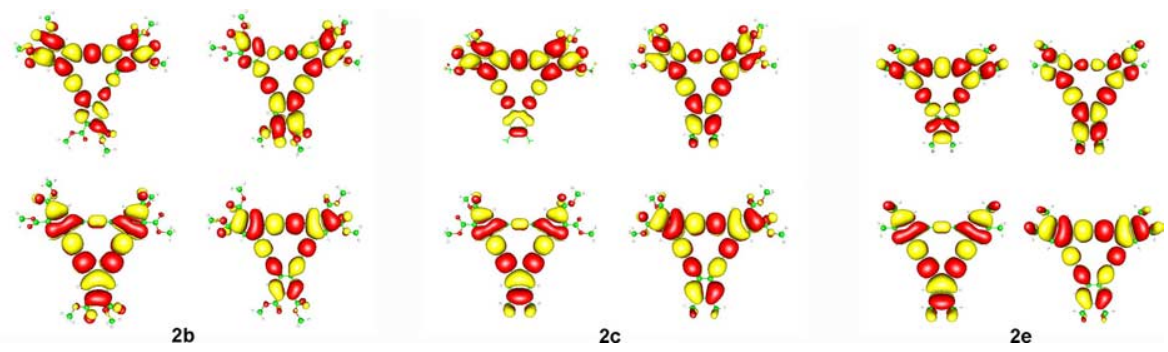

Fig. 4. Plots of degenerate LUMOs (up) and HOMOs (down) of $\mathbf{2 a}, \mathbf{2 b}, \mathbf{2 c}$ and $\mathbf{2 e}$ (2d not shown in order to save space).

reasonable to assume that absorption band at $326 \mathrm{~nm}$ originates from intramolecular charge-transfer (ICT) transition, and thus should show larger solvatochromic shift than other bands in the spectrum of 1c. We measured UV/vis spectra of $1 \mathrm{c}$ in pentane, dichloromethane and 1-decanol (solubility problems precluded measurements in more polar solvents), but the observed shift of only $\sim 5 \mathrm{~nm}$ (Fig. 6), although in the right direction and larger than for the other bands, is too small to be unambiguously attributed to an ICT band. The electron-donating/accepting abilities of the chosen substituents are known to be only weak to moderate but nevertheless, small effects of the ICT in the UV/vis spectra where the general dehydrobenzo[12] annulenic pattern dominates have certainly been observed. The molecular orbital plots (Fig. 3) are fully in accord with these experimental findings. Strong uniform delocalization across the benzoannulenic core present in both the HOMO and LUMO of 1a and 1d confirms the minor influence of the alkyl substitutions on the HOMO-LUMO transition. The LUMO of the alkyl/ester 1c exhibits slight charge transfer from the alkyl to the ester substituents with the central part unchanged.

The spectra of the alkyl/ester-substituted [18]annulenes 2c and 2d showed the same pattern for the dehydrobenzo[18]annulene core with four diagnostic peaks [16] and with the end absorption point extended about $10 \mathrm{~nm}$ more than $\mathbf{2 b}$. With respect to the parent compound $2 \mathbf{a}\left(\mathrm{R}_{1}=\mathrm{H}, \mathrm{R}_{2}=\mathrm{H}\right)$, the spectrum of $2 \mathbf{e}$ is red shifted by only $8 \mathrm{~nm}$, while the spectra of $\mathbf{2 b}, \mathbf{2 c}$ and $\mathbf{2 d}$ (practically coinciding with each other) are red shifted by $16 \mathrm{~nm}$. The doublet of bands at 359 and $369 \mathrm{~nm}$ in unsubstituted 2a is preserved in substituted derivatives but changes its appearance and the two components are not always well resolved [16]. Thus, the second component is easily confused with the very weak band found at $392 \mathrm{~nm}$ in $\mathbf{2 e}$ and at $405 \mathrm{~nm}$ in $\mathbf{2 b}, \mathbf{2 c}$ and $\mathbf{2 d}$. This transition is observable even in unsubstituted 2 at $\sim 390 \mathrm{~nm}$ [5]. Although the alkyl/ester groups in macrocycles $\mathbf{2 c}$ and $\mathbf{2 d}$ do not significantly change electronic absorption spectra, it seems that the observed changes go along with those found in previously published donor/acceptor dehydrobenzo[18]annulenes where aniline and nitro groups were used [16]. The molecular orbital plots (Fig. 4) are consistent with these experimental observations. In the fully alkyl substituted 2e the HOMO and LUMO are unchanged relative to the parent 2a. Some charge rearrangements are seen in $\mathbf{2 c}$ but again due to the forbidden character of the lowest transitions it is not possible to associate them with the shifts in experimental absorption maxima.

Analogously to polycyclic aromatic hydrocarbons, electronic bands of $\mathbf{1}$ and $\mathbf{2}$ are expected to show considerable vibrational fine structure because the chromophores are planar [28]. The bands at 293 and $313 \mathrm{~nm}$ (average values) in $\mathbf{1}$ are separated by $2181 \mathrm{~cm}^{-1}$ and this value should correspond to the triple bond stretching vibration in an electronically excited state. Since, this is close to the values measured for the ground state it might be an indication for the slightly changed geometry of the all-carbon core in the excited state. Since, the calculated lowest absorption should roughly be $100 \mathrm{~nm}$ longer than the HOMO-LUMO gap, weak bands around $520 \mathrm{~nm}$ for $\mathbf{1}$ and $490 \mathrm{~nm}$ for $\mathbf{2}$ should be looked for. However, no data is available on the ionization potentials of our compounds to assess the value of the HOMO-LUMO gap and thus the regions of end absorptions. The HOMO-LUMO gap in [12]annulenes is smaller than in [18] annulenes (Tables 3 and 4) and this would cause the strong red shift of the end absorption of [12] annulenes as compared to [18] annulenes [28]. However, this is correct only if very weak, barely observable absorptions at $\approx 410$ and $\approx 450 \mathrm{~nm}$ (not listed in Table 3) are taken as the real end absorptions in [12]annulenes. No such very weak absorptions above $\approx 405 \mathrm{~nm}$ could have been found in the [18]annulenes. Thus, the strongest absorptions in the UV/vis spectra of $\mathbf{1}$ and $\mathbf{2}$ most probably are not due to the $\mathrm{HOMO} \rightarrow \mathrm{LUMO}$ excitations but due to the $(\mathrm{HOMO}-1) \rightarrow$ LUMO and $\mathrm{HOMO} \rightarrow(\mathrm{LUMO}+1)$ excitations. 

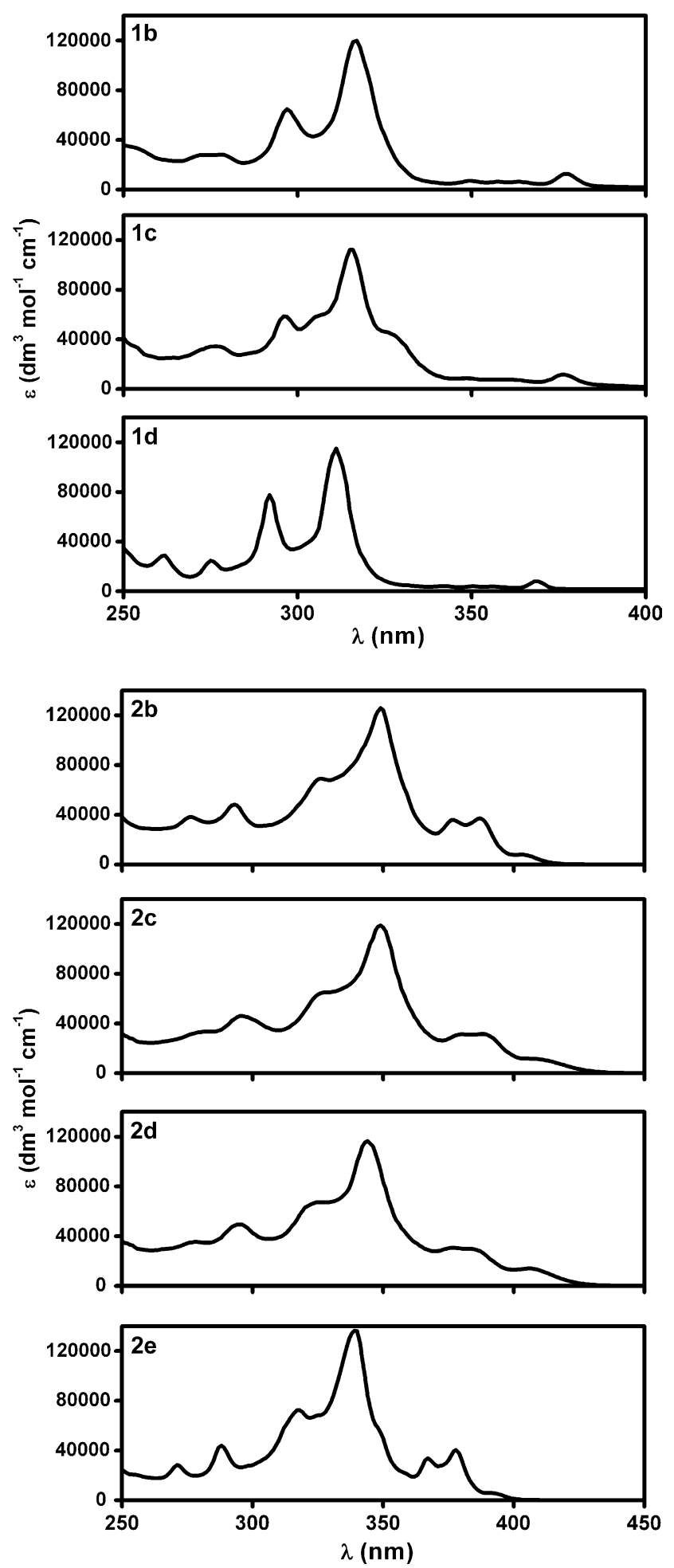

Fig. 5. Electronic absorption spectra of $\mathbf{1}$ and $\mathbf{2}$ in $\mathrm{CHCl}_{3}$.

\subsection{IR and Raman spectra}

As it is very well known the $\mathrm{C} \equiv \mathrm{C}$ absorption in disubstituted acetylenes is mainly affected by the resonance interactions of the substituents with the triple bond ([35] and references therein). In the present case, we are dealing with systems possessing several coupled diacetylenic bridges and it is reasonable to expect similar behavior. Alkyl groups are all weak resonance donors, while ester groups are weak acceptors and redistribution of $\pi$-electron charges in the annulenic core including benzene rings will certainly take place upon substitution. The correlation with Mulliken charges might be useful [35]. The sum of Mulliken charges on all carbon atoms of the benzoannulenic system show that the all-carbon core has donated electrons to alkyl and ester substituents (Tables 5 and 6). This is opposite to what has already been concluded that the all-carbon cores in the systems without fused benzene rings are strong electron acceptors [36]. Unfortunately the calculated charges have not been partitioned into $\pi$ - and $\sigma$-electron charges since only the former are relevant for the resonance effects. The main differences are found for the benzene ring atoms $\mathbf{A}$ and $\mathbf{B}$, while other atoms, $\mathbf{C}, \ldots, \mathbf{H}$, seem to be well protected from the substituents by the same benzene ring.

Assuming $D_{2 h}$ symmetry for a [12] annulene ring, there are four acetylenic bond stretchings, $A_{g}+B_{1 g}+B_{2 u}+B_{3 u}$, i.e. only two of them are expected to be IR active. Vibrational spectra were calculated for molecules having $-\mathrm{CH}_{3}$ group instead of $\mathrm{C}_{10} \mathrm{H}_{21}$. The influence of such modifications in this spectral region, i.e. on the stretching vibrations of the annulenic core, is negligible. The agreement of not only wavenumbers but also relative IR intensities as well with the observed spectra is rather satisfactory (Fig. 7 and Table 7). While the $\mathrm{B}_{2 \mathrm{u}}$ transition remains equally IR active independently of the substitution, the $\mathrm{B}_{3 \mathrm{u}}$ vibration is getting weaker when the acceptor groups replace the donor groups. This is an indication that its intensity should be correlated with the resonance interaction. The atom displacements in the $\mathrm{B}_{3 \mathrm{u}}$ mode are described as simultaneous elongation of the DE and QP bonds accompanied with the contraction of the FG and $\mathbf{O N}$ bonds (Scheme 1). The existence of the permanent molecular dipole moment in 1c along the long molecular axis means that the strong absorption for the totally symmetric mode should occur. Unfortunately the spectra are not of high enough resolution to confirm the prediction that the strongest band in 1c should actually be the symmetric acetylenic stretching. They are also showing two acetylenic IR bands at $\sim 2195$ and $\sim 2125 \mathrm{~cm}^{-1}$ (Fig. 7). A very strong band corresponding to the totally symmetric $\mathrm{C} \equiv \mathrm{C}$ stretching vibration is present at $2191 \mathrm{~cm}^{-1}$ in the Raman spectra of 1 (Table 7). The other Raman active $\mathrm{C} \equiv \mathrm{C}$ stretching modes are weak as in the spectra of alkyl derivatives [37]. Both bands are found in the infrared spectrum of Eglinton-Galbraith dimer $1(\mathrm{R}=\mathrm{H})$ at 2187 and $2116 \mathrm{~cm}^{-1}$ with the same wavenumber difference of $70 \mathrm{~cm}^{-1}$. Contrary to that, in the IR spectra of alkyl derivatives the intensity difference between the two acetylenic bands is getting greater with increasing the size of alkyl substituents and in the spectrum of $\mathbf{1 d}$ the second band cannot be determined [37]. Intensity of the latter band is especially large in the spectra of ester dimers $\mathbf{1 a}$ and $\mathbf{1 b}$. Larger intensity of the band at $2195 \mathrm{~cm}^{-1}$ in the spectrum of donor/ acceptor 1c is clearly visible (Fig. 7). All dimeric compounds 1 show an infrared band at $480 \mathrm{~cm}^{-1}$, which already was described as a characteristic band of the octadehydrodibenzo[12] annulene ring [37]. 
Table 3

Observed UV/vis spectra $\left(\lambda_{\max }\right.$ in $\left.\mathrm{nm}\right)$ of $\mathbf{1}\left(\mathrm{CHCl}_{3}\right)$

\begin{tabular}{|c|c|c|c|c|c|}
\hline $1 a^{a}$ & 1f & $1 b$ & 1c & $1 d$ & Average \\
\hline 252 & & $\approx 274$ & & 262.0 & $263 \pm 11$ \\
\hline 269 & 277.8 & 278.2 & 276.8 & 275.0 & $275 \pm 6$ \\
\hline \multirow[t]{2}{*}{285} & 297.0 & 296.8 & 296.2 & 292.1 & $293 \pm 8$ \\
\hline & & & 307.0 & & 307 \\
\hline 304 & 316.2 & 316.9 & 316.0 & 311.3 & $313 \pm 9$ \\
\hline \multirow[t]{3}{*}{363} & 349.2 & $\approx 350$ & 325.7 & & $350 \pm 14$ \\
\hline & & $\approx 363$ & & & 363 \\
\hline & 376.9 & 377.0 & 375.9 & 368.9 & $375 \pm 6$ \\
\hline $402^{\mathrm{b}}$ & & 430 & 428 & 410 & $418 \pm 16$ \\
\hline
\end{tabular}

a $1 \mathbf{a}$ and 2a refer to the unsubstituted dehydrobenzo[12]annulene and -[18]annulene, respectively. Observed $\lambda_{\max }$ for $1 \mathbf{a}$ from Ref. [18].

b The last row gives the HOMO-LUMO gaps (B3LYP/6-31+ $\mathrm{G}^{*}$, in $\mathrm{nm}$ ).

Table 4

Observed UV/vis spectra $\left(\lambda_{\max }\right.$ in $\left.\mathrm{nm}\right)$ of $2\left(\mathrm{CHCl}_{3}\right)$

\begin{tabular}{|c|c|c|c|c|c|c|}
\hline $2 \mathbf{a}^{\mathrm{a}}$ & $2 f$ & $2 b$ & $2 c$ & $2 d$ & $2 e$ & Average \\
\hline 266 & 275.8 & 275.9 & 282.5 & 278.4 & 271.3 & $275 \pm 7$ \\
\hline 280 & 293.0 & 293.2 & 296.0 & 294.9 & 288.0 & $291 \pm 5$ \\
\hline 309 & 326.1 & 325.8 & 327.7 & 326.5 & $\begin{aligned} & 317.8 \\
\approx & 325\end{aligned}$ & $\begin{array}{l}322 \pm 5 \\
325\end{array}$ \\
\hline 330 & 349.6 & 349.6 & 349.3 & 344.3 & $\begin{aligned} & 339.5 \\
\approx & 350\end{aligned}$ & $\begin{array}{l}344 \pm 5 \\
350\end{array}$ \\
\hline 359 & 376.8 & 376.1 & 378.7 & 376.4 & 367.1 & $372 \pm 6$ \\
\hline 369 & 387.1 & $\begin{aligned} & 387.1 \\
\approx & 405\end{aligned}$ & $\begin{array}{l}387.1 \\
405.8\end{array}$ & $\begin{array}{l}384.8 \\
405.8\end{array}$ & $\begin{aligned} & 377.9 \\
\approx & 393\end{aligned}$ & $\begin{array}{l}382 \pm 5 \\
406 \pm 10\end{array}$ \\
\hline $355^{\mathrm{b}}$ & & 380 & 398 & 396 & 360 & $378 \pm 20$ \\
\hline
\end{tabular}

${ }^{\text {a }}$ Observed $\lambda_{\max }$ for $\mathbf{2 a}$ from Ref. [3]. Very similar to $\mathbf{2 e}$ but uniformly downshifted by $\approx 10 \mathrm{~nm}$.

b HOMO-LUMO gap (B3LYP/6-31 + G* in nm).

Among the vibrations of the [18]annulene ring of $D_{3 h}$ symmetry there are six triple bond stretchings, $\mathrm{A}_{1}{ }^{\prime}+\mathrm{A}_{2}{ }^{\prime}+2 \mathrm{E}^{\prime}$. Only degenerate vibrations should show some IR activity while $\mathrm{A}_{1}{ }^{\prime}$ and $\mathrm{E}^{\prime}$ vibrations are Raman active. According to calculations two pairs should be apart by around $70 \mathrm{~cm}^{-1}$. In the Raman spectra of 2 (Table 8 ) there are two extremely strong bands at 2216 and $2198 \mathrm{~cm}^{-1}$ corresponding to the doubly degenerate and totally symmetric $\mathrm{C} \equiv \mathrm{C}$ stretchings, respectively, (the former band was omitted in the previous paper [37]). In the infrared spectra of trimeric compounds 2 (Table 7) there are three acetylenic bands at $\sim 2215, \sim 2200$ and $\sim 2150 \mathrm{~cm}^{-1}$. Since, the band at $2147 \mathrm{~cm}^{-1}$ does not appear to be split, one component of the doublet observed at around $2210 \mathrm{~cm}^{-1}$ could originate from the strongly Raman active $\mathrm{A}_{1}{ }^{\prime}$ vibration or be a consequence of crystal packing. The doublet is present even in the spectra of symmetrically substituted compounds. While the third band is not found in the spectrum of $\mathbf{2 d}$ its intensity is much larger in the spectra of ester derivatives $\mathbf{2 b}$. As expected, intensity of the acetylenic bands in the spectra of donor/acceptor trimers $\mathbf{2 c}$ and $\mathbf{2 d}$ is considerably larger. The vibrational spectra have been recorded only for the solid phase and the influence of the intermolecular interactions on the vibrational intensities cannot be excluded. However, since the annulenic cores are surrounded by bulky substituents the observed intensity changes actually prove that substituents induce significant intramolecular charge redistribution in the annulene bridges leading to the changed bond polarities, i.e. enhanced IR activity of some $\mathrm{C} \equiv \mathrm{C}$ stretching modes. As for the dimers here again one band might be chosen that best correlates with the resonance interaction. According to the calculated and observed trends in IR intensities, the lower of the two degenerate pairs seems to be most appropriate for the characterization of resonance interactions and the reason being the same as for the $\mathrm{B}_{3 \mathrm{u}}$ vibrations of the dimers. The atom displacements in either of the two lower $\mathrm{E}^{\prime}$ modes are described as simultaneous elongation of the DE and QP bonds accompanied with the contraction of the FG and $\mathbf{O N}$ bonds

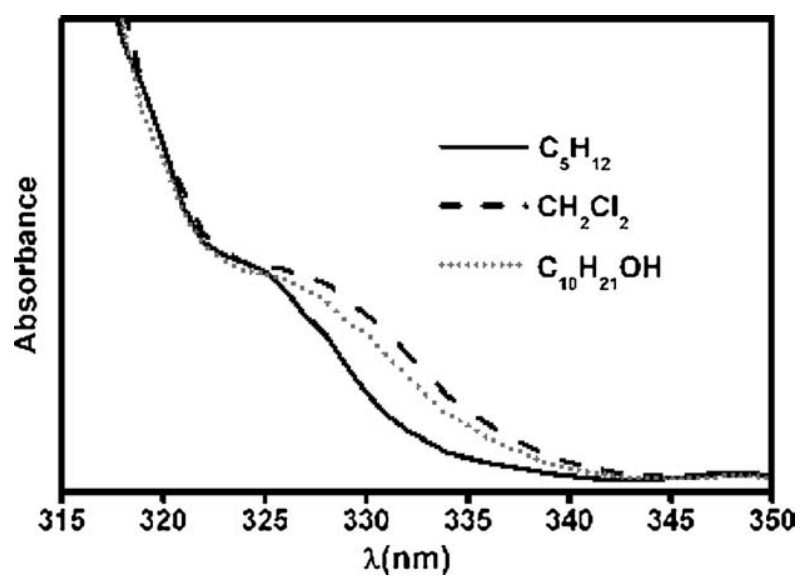

Fig. 6. Electronic absorption spectra of $1 \mathrm{c}$ in different solvents. 
Table 5

Mulliken charges of selected atoms in 1 (Scheme 1)

\begin{tabular}{|c|c|c|c|c|c|}
\hline \multicolumn{2}{|l|}{$1 \mathrm{a}$} & \multicolumn{2}{|l|}{$1 b^{a}$} & \multicolumn{2}{|l|}{$1 d^{b}$} \\
\hline Atom & Charge & Atom & Charge & Atom & Charge \\
\hline A, J & -0.073 & A & 0.638 & A, J & 0.600 \\
\hline $\mathrm{C}, \mathrm{H}$ & -0.351 & $\mathrm{C}$ & -0.441 & $\mathrm{C}, \mathrm{H}$ & -0.617 \\
\hline $\mathrm{D}, \mathrm{G}$ & -0.256 & $\mathrm{D}$ & -0.416 & $\mathrm{D}, \mathrm{G}$ & -0.407 \\
\hline $\mathrm{E}, \mathrm{F}$ & 0.502 & $\mathrm{E}$ & 0.536 & $\mathrm{E}, \mathrm{F}$ & 0.489 \\
\hline & & I & 0.223 & & \\
\hline & & $\mathrm{J}$ & -0.394 & & \\
\hline Sum $^{\mathrm{c}}$ & -1.584 & & -0.130 & & -0.452 \\
\hline$\Delta^{\mathrm{d}}$ & 0 & & 1.454 & & 1.132 \\
\hline
\end{tabular}

a The calculated $\mathbf{1 b}$ structure has $C_{2}$ symmetry with the axis perpendicular to the annulenic plane.

b The calculated 1d structure has $D_{2 h}$ symmetry.

c The sum of Mulliken charges on all the carbon atoms of the benzoannulenic core.

d The difference between the sums of Mulliken charges.

Table 6

Mulliken charges of selected atoms in 2 (Scheme 1)

\begin{tabular}{|c|c|c|c|c|c|}
\hline \multicolumn{2}{|l|}{$2 a$} & \multicolumn{2}{|l|}{$2 b$} & \multicolumn{2}{|l|}{$2 \mathrm{e}$} \\
\hline Atom & Charge & Atom & Charge & Atom & Charge \\
\hline A, J & 0.038 & A & 0.225 & $\mathrm{~A}, \mathrm{~J}$ & 0.585 \\
\hline $\mathrm{B}, \mathrm{I}$ & -0.958 & B & 0.168 & $\mathrm{~B}, \mathrm{I}$ & -0.619 \\
\hline $\mathrm{C}, \mathrm{H}$ & 0.443 & $\mathrm{C}$ & 0.122 & $\mathrm{C}, \mathrm{H}$ & -0.292 \\
\hline $\mathrm{D}, \mathrm{G}$ & -0.985 & D & -1.202 & $\mathrm{D}, \mathrm{G}$ & -1.018 \\
\hline \multirow[t]{8}{*}{$\mathrm{E}, \mathrm{F}$} & 1.062 & $\mathrm{E}$ & 1.052 & $\mathrm{E}, \mathrm{F}$ & 1.070 \\
\hline & & $\mathrm{F}$ & 1.101 & & \\
\hline & & $\mathrm{G}$ & -1.224 & & \\
\hline & & $\mathrm{H}$ & 0.005 & & \\
\hline & & I & 0.192 & & \\
\hline & & $\mathrm{J}$ & -0.680 & & \\
\hline & & $\mathrm{K}$ & 0.225 & & \\
\hline & & $\mathrm{L}$ & 0.168 & & \\
\hline Sum $^{\mathrm{a}}$ & -2.400 & & 0.456 & & -1.644 \\
\hline$\Delta^{\mathrm{b}}$ & 0 & & 2.856 & & 0.756 \\
\hline
\end{tabular}

a The sum of Mulliken charges on all the carbon atoms of the benzoannulenic core.

b The difference between the sums of Mulliken charges.
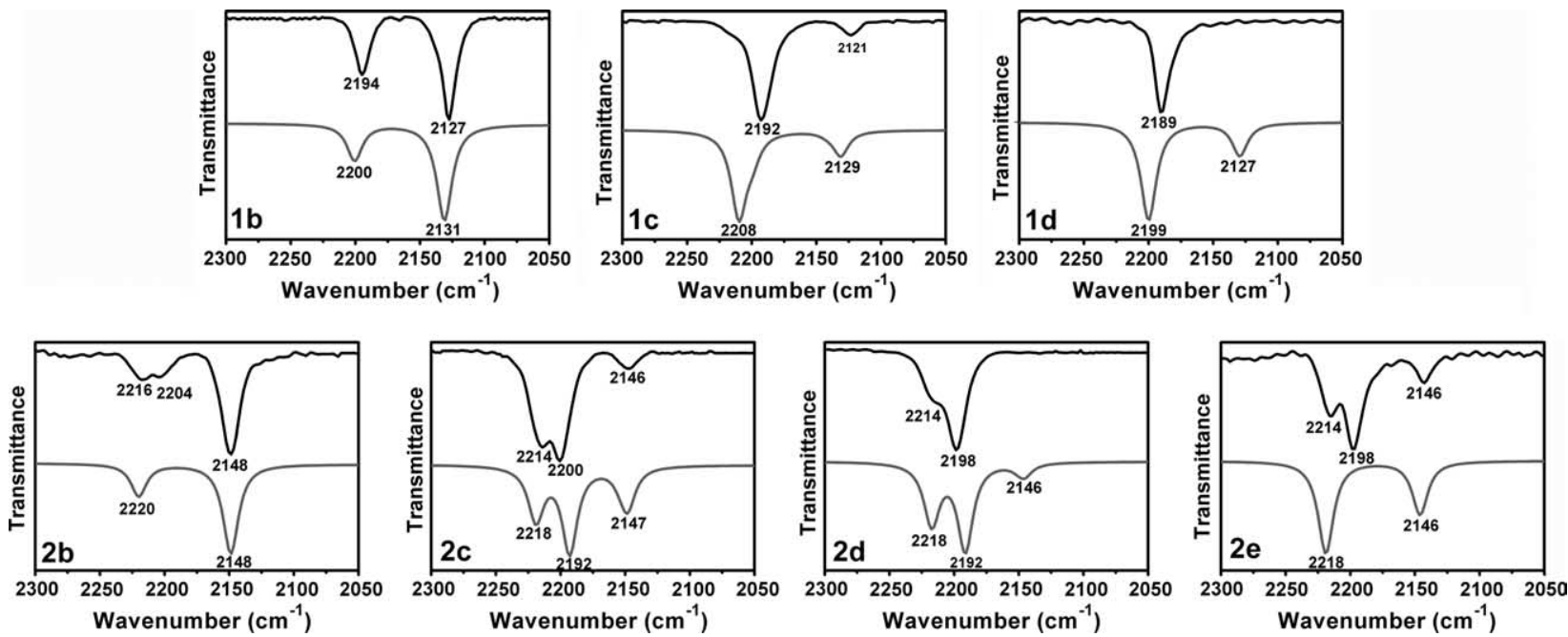

Fig. 7. Observed (black) IR acetylenic bands of $\mathbf{1}$ and $\mathbf{2}$ normalized relative to common alkyl band at $2920 \mathrm{~cm}^{-1}$ (KBr pellets) and calculated (gray). 
Table 7

Observed and calculated wavenumbers and IR intensities of $\mathbf{1}$ in the region of acetylenic stretchings

\begin{tabular}{|c|c|c|c|c|c|c|c|c|c|c|}
\hline \multicolumn{2}{|l|}{$1 \mathbf{a}$} & \multicolumn{3}{|l|}{$1 b$} & \multicolumn{3}{|l|}{ 1c } & \multicolumn{3}{|l|}{ 1d } \\
\hline $\mathrm{IR}^{\mathrm{a}}$ & Calc. $^{\mathrm{b}}$ & $\mathrm{IR}^{\mathrm{c}}$ & $\mathrm{R}^{\mathrm{d}}$ & Calc. $^{\mathrm{b}}$ & $\mathrm{IR}^{\mathrm{c}}$ & $\mathrm{R}^{\mathrm{d}}$ & Calc. $^{\mathrm{b}}$ & $\mathrm{IR}^{\mathrm{c}}$ & $\mathrm{R}^{\mathrm{d}}$ & Calc. $^{\mathrm{b}}$ \\
\hline \multirow{3}{*}{$2187 \mathrm{~s}$} & $2210 \mathrm{~A}_{\mathrm{g}} 0.0$ & & $2198 s$ & 2209 A 0.0 & $2192 s$ & 2191s & 2208 A 83.6 & & $2198 \mathrm{~s}$ & $2208 \mathrm{~A}_{\mathrm{g}} 0.0$ \\
\hline & $2201 \mathrm{~B}_{2 \mathrm{u}} 14.6$ & $2194 \mathrm{~m}^{\mathrm{e}}$ & & 2200 B 20.0 & $\mathrm{sh}$ & & 2198 A 20.0 & $2189 \mathrm{~s}$ & & $2199 \mathrm{~B}_{2 \mathrm{u}} 20.5$ \\
\hline & $2140 \mathrm{~B}_{1 \mathrm{~g}} 0.0$ & & $2136 w$ & 2141 A 0.0 & & $2133 w$ & 2139 A 2.2 & & $2128 w$ & $2138 \mathrm{~B}_{1 \mathrm{~g}} 0.0$ \\
\hline $2116 \mathrm{~m}$ & $2130 \mathrm{~B}_{3 \mathrm{u}} 17.3$ & $2127 \mathrm{~s}$ & & 2131 В 52.9 & $2121 w$ & & 2129 A 24.5 & $-{ }^{\mathrm{f}}$ & & $2127 \mathrm{~B}_{3 \mathrm{u}} 6.9$ \\
\hline
\end{tabular}

a Ref. [18].

b Scaled by 0.963 [37].

c $\mathrm{IR}(\mathrm{KBr})$.

d Raman (powder).

e s, strong in this region; $\mathrm{m}$, medium; w, weak; sh, shoulder.

f Not observed.

Table 8

Observed and calculated wavenumbers and IR intensities of $\mathbf{2}$ in the region of acetylenic stretchings

\begin{tabular}{|c|c|c|c|c|c|c|c|c|c|c|c|c|c|}
\hline \multicolumn{2}{|l|}{$2 \mathbf{a}$} & \multicolumn{3}{|l|}{$2 b$} & \multicolumn{3}{|l|}{$2 c$} & \multicolumn{3}{|l|}{$2 d$} & \multicolumn{3}{|l|}{$2 \mathrm{e}$} \\
\hline $\mathrm{IR}^{\mathrm{a}, \mathrm{b}}$ & Calc. $^{\mathrm{c}}$ & $\mathrm{IR}^{\mathrm{a}}$ & $\mathrm{R}^{\mathrm{d}}$ & Calc. & $\mathrm{IR}^{\mathrm{a}}$ & $\mathrm{R}^{\mathrm{d}}$ & Calc. & $\mathrm{IR}^{\mathrm{a}}$ & $\mathrm{R}^{\mathrm{d}}$ & Calc. & $\mathrm{IR}^{\mathrm{a}}$ & $\mathrm{R}^{\mathrm{d}}$ & Calc. \\
\hline \multirow[t]{9}{*}{$2207 \mathrm{~s}$} & $\begin{array}{l}2221 \mathrm{E}^{\prime} \\
2.7\end{array}$ & 2216w & $2218 \mathrm{~m}$ & $\begin{array}{l}2220 \mathrm{E} \\
12.8\end{array}$ & & $2216 \mathrm{~m}$ & $\begin{array}{l}2219 \mathrm{~A} \\
15.6\end{array}$ & & & $\begin{array}{l}2219 \mathrm{~A} \\
43.5\end{array}$ & $2214 \mathrm{~m}$ & $2214 \mathrm{~m}$ & $\begin{array}{l}2218 \mathrm{E}^{\prime} \\
3.1\end{array}$ \\
\hline & $\begin{array}{l}2221 \mathrm{E}^{\prime} \\
2.7\end{array}$ & 2204w & & $\begin{array}{l}2220 \mathrm{E} \\
12.8\end{array}$ & $2214 m$ & & $\begin{array}{l}2218 \mathrm{~B} \\
37.6\end{array}$ & 2214 sh & & $\begin{array}{l}2217 \mathrm{~A} \\
41.6\end{array}$ & $2198 \mathrm{~s}$ & & $\begin{array}{l}2218 \mathrm{E}^{\prime} \\
3.1\end{array}$ \\
\hline & $\begin{array}{l}2195 \mathrm{~A}_{1}{ }^{\prime} \\
0.0\end{array}$ & & $2201 \mathrm{~s}$ & $\begin{array}{l}2194 \mathrm{~A} \\
0.0\end{array}$ & $2200 \mathrm{~m}$ & $2199 \mathrm{~s}$ & $\begin{array}{l}2192 \mathrm{~A} \\
84.8\end{array}$ & $2198 \mathrm{~s}$ & & $\begin{array}{l}2192 \mathrm{~A} \\
120.1\end{array}$ & & $2197 \mathrm{~s}$ & $\begin{array}{l}2192 \mathrm{~A}_{1}{ }^{\prime} \\
0.0\end{array}$ \\
\hline & $2153 \mathrm{~A}_{2}^{\prime}$ & & & $2154 \mathrm{~A}$ & & & $2153 \mathrm{~B}$ & & & $2152 \mathrm{~A}$ & & & $2151 \mathrm{~A}_{2}^{\prime}$ \\
\hline & 0.0 & & & 0.0 & & & 6.8 & & & 2.1 & & & 0.0 \\
\hline & $2147 \mathrm{E}^{\prime}$ & $2148 \mathrm{~s}$ & & $2148 \mathrm{E}$ & $2146 w$ & & $2147 \mathrm{~B}$ & & & $2146 \mathrm{~A}$ & $2146 w$ & & $2146 \mathrm{E}^{\prime}$ \\
\hline & 8.3 & & & 35.4 & & & 32.6 & & & 14.0 & & & 1.8 \\
\hline & $2147 \mathrm{E}^{\prime}$ & & & $2148 \mathrm{E}$ & & & $2147 \mathrm{~A}$ & & & $2145 \mathrm{~A}$ & & & $2146 \mathrm{E}^{\prime}$ \\
\hline & 8.3 & & & 35.4 & & & 8.4 & & & 4.9 & & & 1.8 \\
\hline
\end{tabular}

${ }^{\text {a }} \operatorname{IR}(\mathrm{KBr})$.

b No other bands listed [5].

c Scaled by 0.963 [37].

d Raman (powder).

while the carbon atoms of the third acetylenic bridge are practically motionless (Scheme 1). However, the most sensitive again is the totally symmetric mode $\mathrm{A}_{1}{ }^{\prime}$ which causes the greatest changes of the permanent dipole moment.

The strongest Raman modes in $\mathbf{1 c}, \mathbf{2 c}$ and $\mathbf{2 d}$ also exhibit strong IR activity and therefore, these compounds are expected to have large vibrational hyperpolarizibilities [15]. The same mode is also expected to be strongly coupled with the first allowed electronic transition. It is now obvious that the totally symmetrical acetylenic stretching in either case is an effective conjugation coordinate [38].

\section{Conclusions}

In summary, we have reported the preparation, characterization and structure determination of the Eglinton-Galbraith dimer derivatives with electron acceptor (1b) and donor (1d) groups, and analogous trimeric macrocycles $\mathbf{2 b}$ and $\mathbf{2 e}$, along with donor/acceptor substituted macrocycles $\mathbf{1 c}, \mathbf{2 c}$ and $\mathbf{2 d}$. Using the intermolecular route [16] we have nevertheless, succeeded in obtaining the product of $C_{2 v}$ symmetry in macroscopic amounts. Contrary to the previous research [14] we conclude that dimeric compounds are in the solid phase predominantly stabilized by bulky substituents whereas the donor or acceptor nature of substituents has far less influence. According to our knowledge dimeric macrocycle 1c is the first example of push-pull Eglinton-Galbraith dimer derivative. Although IR spectra of the compounds 1c, 2c and 2d show significant intensity, i.e. charge redistribution in the benzoannulenic ring, it is not sufficient to induce dramatic shifts in the corresponding UV/vis spectra. Since, the extreme polarization of the conjugated backbone is present in some push-pull dehydrobenzo[18]annulenes [16], it seems that lack of its occurrence in the case of our compounds can be attributed to weak electron-donor and -acceptor properties of alkyl and ester substituents. Similar level of annulenic ring polarization in the dimer $\mathbf{1 c}$ and trimers $\mathbf{2 c}$ and $\mathbf{2 d}$ therefore, suggests that substantial polarization of the conjugated backbone in the dimeric dehydrobenzo[12] annulene could be induced by other electron-donor and -acceptor groups (specifically, amino and nitro groups), thus creating good candidates for use as novel photonic materials. Most important advantage of dehydrobenzo[12] annulenes over trimeric dehydrobenzo[18]annulenes is their greater solubility which is very important regarding 
common poor solubility of dehydrobenzoannulenes. On the other hand, even though these dimeric macrocycles are quite stable at room temperature, they are decomposing more rapidly and at much lower temperatures than their trimeric counterparts $[14,16]$.

\section{Acknowledgements}

This work was supported by the Ministry of Education, Science and Sport of the Republic of Croatia (Project no. 0098057). The generous supply of experimental time on the Raman spectrometer by Prof. Z. Meić (Department of Analytical Chemistry, Faculty of Sciences, University of Zagreb) is gratefully acknowledged.

\section{Supplementary data}

Supplementary data (synthesis and full characterization of all compounds) associated with this article can be found, in the online version, at doi:10.1016/j.molstruc.2006.01.049. [39]

\section{References}

[1] J.A. Marsden, M.M. Haley, J. Org. Chem. 70 (2005) 10213

[2] W. Brad Wan, M.M. Haley, J. Org. Chem. 66 (2001) 3893.

[3] W. Brad Wan, S.C. Brand, J.J. Pak, M.M. Haley, Chem. Eur. J. 6 (2000) 2044

[4] U.H.F. Bunz, Y. Rubin, Y. Tobe, Chem. Soc. Rev. 28 (1999) 107.

[5] M.M. Haley, S.C. Brand, J.J. Pak, Angew. Chem. Int. Ed. 36 (1997) 836.

[6] R.H. Baughman, H. Eckhardt, M. Kertesz, J. Chem. Phys. 87 (1987) 6687.

[7] F. Diederich, Nature 369 (1994) 199.

[8] M.M. Haley, Synth. Lett. (1998) 557.

[9] M.M. Haley, J.J. Pak, S.C. Brand, Topp. Curr. Chem. 201 (1999) 81.

[10] J.A. Marsden, G.J. Palmer, M.M. Haley, Eur. J. Org. Chem. (2003) 2355.

[11] J. Anthony, A.M. Boldi, C. Boudon, J.P. Gisselbrecht, M. Gross, P. Seiler, C.B. Knobler, F. Diederich, Helv. Chim. Acta 78 (1995) 797.

[12] T. Nishinaga, Y. Miyata, N. Nodera, K. Komatsu, Tetrahedron 60 (2004) 3375 .

[13] J.D. Tovar, N. Jux, T. Jarrosson, S.I. Khan, Y. Rubin, J. Org. Chem. 63 (1998) 4856.

[14] Q. Zhou, P.J. Carroll, T.M. Swager, J. Org. Chem. 59 (1994) 1294.

[15] X. Zhou, A.-M. Reu, J.-K. Feng, X.-J. Liu, Can. J. Chem. Rev. Can. Chim. 82 (2004) 1172

[16] J.J. Pak, T.J.R. Weakley, M.M. Haley, J. Am. Chem. Soc. 121 (1999) 8182
[17] S.A. Sarkar, J.J. Pak, G.W. Rayfield, M.M. Haley, J. Mater. Chem. 11 (2001) 2943.

[18] O.M. Behr, G. Eglinton, A.R. Galbraith, R.A. Raphael, J. Chem. Soc (1960) 3614

[19] U.H.F. Bunz, V. Enkelmann, Chem. Eur. J. 5 (1999) 263.

[20] T. Nishinaga, H. Nakayama, N. Nodera, K. Komatsu, Tetrahedron Lett 39 (1998) 7139

[21] T. Nishinaga, N. Nodera, Y. Miyata, K. Komatsu, J. Org. Chem. 67 (2002) 6091.

[22] K. Harms, S. Wocadlo, University of Marburg, Marburg, Germany, 1995.

[23] L.J. Farrugia, J. Appl. Crystallogr. 32 (1999) 837.

[24] G.M. Sheldrick, SHELx97: Program for the Refinement of Crystal Structures, Universität of Göttingen, Germany, 1997.

[25] A.L. Spek, PLATON98: A Multipurpose Crystallographic Tool 101201 Version, University of Utrecht, Utrecht, The Netherlands, 2001.

[26] M.J. Frisch, G.W. Trucks, H.B. Schlegel, G.E. Scuseria, M.A. Robb, J.R. Cheeseman, J.A. Montgomery, Jr., T. Vreven, K.N. Kudin, J.C. Burant, J.M. Millam, S.S. Iyengar, J. Tomasi, V. Barone, B. Mennucci, M. Cossi, G. Scalmani, N. Rega, G.A. Petersson, H. Nakatsuji, M. Hada, M. Ehara, K. Toyota, R. Fukuda, J. Hasegawa, M. Ishida, T. Nakajima, Y. Honda, O. Kitao, H. Nakai, M. Klene, X. Li, J.E. Knox, H.P. Hratchian, J.B. Cross, C. Adamo, J. Jaramillo, R. Gomperts, R.E. Stratmann, O. Yazyev, A.J. Austin, R. Cammi, C. Pomelli, J.W. Ochterski, P.Y. Ayala, K. Morokuma, G.A. Voth, P. Salvador, J.J. Dannenberg, V.G. Zakrzewski, S. Dapprich, A.D. Daniels, M.C. Strain, O. Farkas, D.K. Malick, A.D. Rabuck, K. Raghavachari, J.B. Foresman, J.V. Ortiz, Q. Cui, A.G. Baboul, S. Clifford, J. Cioslowski, B.B. Stefanov, G. Liu, A. Liashenko, P. Piskorz, I Komaromi, R.L. Martin, D.J. Fox, T. Keith, M.A. Al-Laham, C.Y. Peng, A. Nanayakkara, M. Challacombe, P.M.W. Gill, B. Johnson, W. Chen, M.W. Wong, C. Gonzalez, J.A. Pople, Gaussian 03, Revision C.02, Gaussian, Inc., Wallingford, CT, 2004.

[27] W. Koch, M.C. Holthausen, A Chemist's Guide to Density Functional Theory, second ed., Wiley-VCH, New York, 2001.

[28] J. Anthony, C.B. Knobler, F. Diederich, Angew. Chem. Int. Ed. Engl. 32 (1993) 406.

[29] F.R. Fronczek, M.S. Erickson, J. Chem. Cryst. 25 (1995) 737.

[30] L. Guo, J.D. Bradshaw, C.A. Tessier, W.J. Youngs, J. Chem. Soc. Chem. Commun. (1994) 243.

[31] J. Juselius, D. Sundholm, Phys. Chem. Chem. Phys. 3 (2001) 2433.

[32] A.J. Boydston, M.M. Haley, Org. Lett. 3 (2001) 3599.

[33] J.A. Marsden, J.J. Miller, L.D. Shirtcliff, M.M. Haley, J. Am. Chem. Soc. 127 (2005) 2464.

[34] M.E. Gallagher, J.E. Anthony, Tetrahedron Lett. 42 (2001) 7533.

[35] A.R. Katritzky, R.D. Topsom, Chem. Rev. 77 (1977) 639.

[36] F. Mitzel, C. Boudon, J.-P. Gisselbrecht, M. Gross, F. Diederich, Chem. Commun. (2002) 2318.

[37] N. Biliškov, B. Zimmermann, G. Baranović, J. Mol. Struct. 661 (2003) 65

[38] M. Tommasini, C. Castiglioni, M. Del Zoppo, G. Zerbi, J. Mol. Struct. 480/481 (1999) 179.

[39] Q. Zhou, T.M. Swager, J. Am. Chem. Soc. 117 (1995) 12593. 